\title{
Intestinal permeability before and after ibuprofen in families of children with Crohn's disease
}

\author{
Samuel A Zamora $\mathrm{MD}^{1}$, Robert J Hilsden $\mathrm{MD}^{2}$, Jon B Meddings $\mathrm{MD}^{3}$, J Decker Butzner $\mathrm{MD}^{1}$, \\ $\mathrm{R}$ Brent Scott $\mathrm{MDCM}^{1}$, Lloyd R Sutherland $\mathrm{MD}^{2}$
}

SA Zamora, RJ Hilsden, JB Meddings, JD Butzner, RB Scott, LR Sutherland. Intestinal permeability before and after ibuprofen in families of children with Crohn's disease. Can J Gastroenterol 1999;13(1):31-36.

BACKGROUND: Members of a subset of first-degree relatives of adults with Crohn's disease have been shown to have an increased baseline intestinal permeability and/or an exaggerated increase in intestinal permeability after the administration of acetylsalicylic acid.

PURPOSE: To determine intestinal permeability in unaffected first-degree relatives of children with Crohn's disease before and after the administration of an ibuprofen challenge.

METHODS: Lactulose-mannitol ratios, a measure of intestinal permeability, were determined in 14 healthy control families (41 subjects) and 14 families with a child with Crohn's disease ( 36 relatives, 14 probands) before and after ingestion of ibuprofen. An upper reference limit was defined using the control group as mean \pm 2 SD.

RESULTS: The proportion of healthy, first-degree relatives with an exaggerated response to ibuprofen $(20 \%, 95 \% \mathrm{CI} 7 \%$ to $33 \%)$ was significantly higher than controls $(P=0.003)$. The exaggerated response was more common among siblings than among parents of pediatric probands.
CONCLUSIONS: Members of a subset of first-degree relatives of children with Crohn's disease have an exaggerated increase in intestinal permeability after ibuprofen ingestion. These findings are compatible with there being a genetic link between abnormalities of intestinal permeability and Crohn's disease.

Key Words: Crohn's disease, Inflammatory bowel disease, Intestinal permeability, Nonsteroidal anti-inflammatory drugs (NSAIDs)

\section{Perméabilité intestinale avant et après} l'ibuprofène dans des familles d'enfants atteints de maladie de Crohn

HISTORIQUE : On a découvert chez les membres d'une sous-série de parents proches d'adultes atteints de la maladie de Crohn, une perméabilité intestinale de base accrue et/ou un accroissement de la perméabilité intestinale après l'administration d'acide acétylsalicylique. BUT : Déterminer la perméabilité intestinale chez des parents proches non atteints d'enfants porteurs d'une maladie de Crohn avant et après l'administration d'ibuprofène en test de provocation.

MÉTHODE : Les ratios lactulose-mannitol, une mesure de la perméabilité intestinale, ont été calculés avant, puis après l'ingestion d'ibuprofène chez 14 familles témoins en bonne santé (41 sujets)

Departments of Pediatrics ${ }^{1}$, Community Health Sciences ${ }^{2}$ and Medicine ${ }^{3}$, Health Science Centre, Calgary, Alberta Correspondence and reprints: Dr R Brent Scott, Department of Pediatrics, Health Science Centre, 3330 Hospital Drive NW, Calgary, Alberta T2N 4N1. Telephone 403-220-4556, fax 403-283 3028, e-mail scott@acs.ucalgary.ca

Received for publication March 11, 1998. Accepted July 7, 1998 
et 14 familles dont un enfant est atteint de la maladie de Crohn (36 parents, 14 probants). On a défini la limite supérieure de référence à l'aide du groupe témoin comme la moyenne \pm 2 écarts types.

RÉSULTATS : La proportion de parents proches en bonne santé présentant une réponse exagérée à l'ibuprofène $(20 \%$, IC $95 \%, 7$ $\%$ à $33 \%)$ a été significativement plus grande chez les témoins ( $\mathrm{p}=$
$0,03)$. La réponse exagérée a été plus courante chez les enfants que chez les parents des probants pédiatriques.

CONCLUSIONS : Les membres d'une sous-série de parents proches d'enfants atteints de maladie de Crohn présentent un accroissement exagéré de la perméabilité intestinale après l'administration d'ibuprofène. Ces résultats concordent avec l'existence d'un lien
$\mathrm{T}$ he etiology of Crohn's disease remains unknown; however, genetic and environmental factors are believed to contribute to the development of the disease. The familial aggregation of inflammatory bowel disease (Crohn's disease and/or ulcerative colitis), which may be attributed to either genetic or environmental factors, is well recognized, with a $5 \%$ to $20 \%$ likelihood of finding inflammatory bowel disease in relatives of a proband (1-5). A recent survey determining familial empirical risk of inflammatory bowel disease estimated that between 5\% and $8 \%$ of first-degree relatives of affected patients will develop Crohn's disease in their lifetime (6).

One approach to the identification of a genetic cause of a given disorder is to search for clinical or phenotypic markers, the occurence of which may mark the presence of specific candidate genes that might predispose to the development of the disorder - in this instance, Crohn's disease. Hollander et al (7) were the first to report increased intestinal permeability in healthy, first-degree relatives of patients with Crohn's disease and suggest that a familial permeability defect may play a role in the pathogenesis of the disease. However, subsequent studies have failed to confirm this finding (8-15). One explanation for these conflicting results is that not all first-degree relatives are expected to share a permeability defect. As a result, when mean values of intestinal permeability are compared between relatives and controls, the magnitude of the difference may be small, making it necessary to have a very large sample size to avoid a type II error (16). A second explanation is that the permeability defect in first-degree relatives may manifest only after a provocative test with a nonsteroidal anti-inflammatory drug (NSAID) (17). Thirty-five per cent of relatives of adults with Crohn's disease exhibited an exaggerated increase in intestinal permeability in response to acetylsalicylic acid (ASA), which is consistent with the latter hypothesis. Evaluation of the limited number of patient-relative pairs within the study population suggested concordance in the permeability results among family members with Crohn's disease (18).

The objectives of the present study were to measure intestinal permeability before and after an ibuprofen challenge in families (first-degree relatives) of children with Crohn's disease and to examine concordance in permeability results among family members. Children were studied because the familial aggregation of Crohn's disease has been shown to be associated with a lower age of onset in affected individuals of successive generations (19-22). Stud- ies of affected parent-child pairs have shown that parents are between five and 15 years older than children at onset $(20,23,24)$. This is compatible with either a greater genetic susceptability in patients who develop inflammatory bowel disease at a younger age or genetic anticipation, the tendency for successive generations to develop disease of increasing severity and earlier onset. A single rather than multiple dose regimen of the drug ibuprofen was selected for the NSAID challenge for simplicity and feasibility. It was felt that the simpler single dose would improve recruitment and reduce dropout from poor compliance or adverse effects. The NSAID ibuprofen was selected because we thought that parental concern over the use of ASA, which has been linked to Reye's syndrome in children, might limit recruitment.

\section{SUBJECTS AND METHODS}

Subjects: The study was approved by the Conjoint Medical Regional Ethics Board representing the University of Calgary and the Calgary Regional Health Association, and written informed consent was obtained from participating families. Of all the families of children with Crohn's disease followed at the Gastroenterology Clinic at Alberta Children's Hospital, 31 met the inclusion criteria of having a child with Crohn's disease in clinical remission, assessed by the attending pediatric gastroenterologist using a previously validated pediatric Crohn's disease activity index (25). Seven families refused to participate because the proband did not agree to do the test. Among the 24 remaining families who gave informed consent, 14 children (less than 18 years of age) with Crohn's disease and their complete families (36 first-degree relatives of children with Crohn's disease) completed the permeability studies. Fourteen healthy families (recruited from the out-patient fracture clinic and the families of staff at Alberta Children's Hospital) comprised the control group (41 family members). All relatives and controls were free of gastrointestinal symptoms. Asymptomatic relatives and controls were not investigated to identify undiagnosed Crohn's disease. Exclusion criteria for the families of healthy control children or families with an index child affected by Crohn's disease were regular use of ASA/NSAID (at least once a week), allergy or contraindication to ibuprofen, diabetes mellitus, renal insufficiency and, for children with Crohn's disease, clinical relapse.

Study protocol: Subjects were instructed not to consume alcohol or NSAID for at least three days before permeabil- 
ity testing. Participants consumed the test solution before bedtime and after a fast of at least $1 \mathrm{~h}$. The test solution contained lactulose $5 \mathrm{~g}$ (Technilab) and mannitol $2 \mathrm{~g}$ (BDH Chemicals Inc) in $100 \mathrm{~mL}$ of water (osmolarity 273 osmol/L). Children received $2 \mathrm{~mL} / \mathrm{kg}$ (maximum $100 \mathrm{~mL}$ ) of the test solution (lactulose $0.1 \mathrm{~g} / \mathrm{kg}$ and mannitol 0.04 $\mathrm{g} / \mathrm{kg}$ ) and adults $100 \mathrm{~mL}$. Subjects voided before drinking the test solution and then collected all urine including the first morning void in containers with $5 \mathrm{~mL}$ of $10 \%$ thymol in methanol. Subjects underwent two permeability tests - a baseline and a postibuprofen test. The second test was done one to five days after the baseline test. A pilot study in adults determined that an $800 \mathrm{mg}$ dose of ibuprofen produced a percentage change in lactolose-mannitol (LM) ratio similar to that reported in response to ASA (18). On this basis, an oral dose of ibuprofen (adults: $800 \mathrm{mg}$; children $10 \mathrm{mg} / \mathrm{kg}$ to a maximum dose of $800 \mathrm{mg}$ ) was administered, and $1 \mathrm{~h}$ later subjects consumed the test solution and collected urine in an identical fashion to that for the baseline permeability test. One child with Crohn's disease and one subject in the relatives group had an intolerance to NSAID and did not perform the ibuprofen challenge.

Analytical methods: Urine samples were kept refrigerated until analysis. Urine samples $(10 \mathrm{~mL})$ were deionized by adding $1 \mathrm{~g}$ of a 1:1.5 (wt/wt) mixture of Amberlite IR-120 and IRA-400 resin (BDH Chemicals Inc). Following centrifugation at $700 \mathrm{~g}$ for $10 \mathrm{mins}$, the supernatant was filtered through a $40 \mu \mathrm{m} / \mathrm{L}$ Millipore filter (Millipore, Massachusetts). Samples were separated on a Dionex MA-1 anion exchange column in a Dionex HPLC (Dionex) at room temperature using $500 \mathrm{mmol} / \mathrm{L}$ sodium hydroxide as the isocratic mobile phase. Peak identification was accomplished with the use of authentic standards and detected using pulsed amperometric electrochemical detection on a gold electrode. Samples were diluted as necessary after addition of cellobiose as an internal standard.

Sample concentrations were quantified using linear interpolation between concentrations of known standards at multiple concentrations. All samples were diluted so that concentrations of interest fell within the range of the standards.

The fractional excretion of each probe was determined
TABLE 1

Demographic characteristics of controls, Crohn's disease children and their relatives

\begin{tabular}{lccccc}
\hline & \multicolumn{2}{c}{ Controls } & Crohn's & \multicolumn{2}{c}{ Relatives } \\
& $\begin{array}{c}\text { Parents } \\
(\mathbf{n = 2 0})\end{array}$ & $\begin{array}{c}\text { Children } \\
(\mathbf{n = 2 1})\end{array}$ & $\begin{array}{c}\text { Children } \\
(\mathbf{n = 1 4})\end{array}$ & $\begin{array}{c}\text { Parents } \\
(\mathbf{n = 2 3})\end{array}$ & $\begin{array}{c}\text { Children } \\
(\mathbf{n = 1 3 )}\end{array}$ \\
\hline $\begin{array}{c}\text { Age, median } \\
\text { (range) }\end{array}$ & 40 & 13 & 14 & 40 & 13 \\
Female/male & $(32-49)$ & $(6-17)$ & $(6-17)$ & $(31-64)$ & $(8-17)$ \\
Current smokers & $13 / 7$ & $8 / 13$ & $3 / 11$ & $13 / 10$ & $6 / 7$ \\
& $6 / 20$ & - & - & $4 / 23$ & - \\
& $(30 \%)$ & & & $(17 \%)$ & \\
\hline
\end{tabular}

by calculating the proportion of the ingested probe that was excreted in the urine. The LM ratio was obtained by dividing the fractional excretion of lactulose by the fractional excretion of mannitol. The LM ratio represents the measure of intestinal permeability. To account for the baseline level of intestinal permeability in each individual, the percentage change in LM ratio after ibuprofen was used as the main measure of interest, reflecting the response to the NSAID challenge. This ratio was calculated as follows:

$$
=\frac{\text { Percentage change in LM ratio }}{\text { baseline LM ratio }} \times 100(\%)
$$

Statistical analysis: Analyses were performed using the statistical software Stata 5.0 (Stata Corporation, Texas). All statistical tests are two-sided with an alpha level of 0.05 . Descriptive statistics were performed on baseline characteristics of children with Crohn's disease and their firstdegree relatives, and controls. Baseline LM ratios did not appear to have a normal distribution and are, therefore, expressed as median and range. The percentage change in LM ratio postibuprofen was normally distributed, and data are means $\pm \mathrm{SE}$. Baseline LM ratios were compared among groups by using the Mann-Whitney $U$ test. Changes in LM ratio postibuprofen were compared among study groups by using $t$ tests. An upper reference limit was defined as mean \pm 2 SD of the data from the control population. For base-

TABLE 2

Baseline lactulose-mannitol (LM) ratio, postibuprofen change in LM ratio (\%) and proportion of controls, Crohn's disease children and their relatives with an exaggerated response to ibuprofen

\begin{tabular}{lcccccc}
\hline & \multicolumn{2}{c}{ Controls } & Crohn's & \multicolumn{2}{c}{ Relatives } \\
& Parents $(\mathbf{n}=\mathbf{2 0})$ & Children $\mathbf{( n = 2 1 )}$ & Children* $(\mathbf{n = 1 4})$ & Parents* $(\mathbf{n}=\mathbf{2 3})$ & Children $(\mathbf{n}=\mathbf{1 3})$ \\
\hline LM ratio: median (range) & 0.0144 & 0.0189 & 0.0271 & 0.0155 & 0.0197 \\
& $(0.0067-0.0289)$ & $(0.0120-0.0532)$ & $(0.0139-0.1735)$ & $(0.0092-0.0349)$ & $(0.0110-0.0549)$ \\
Percentage change in LM ratio, mean (SE) & $38(11)$ & $32(8)$ & $81(43)$ & $44(14)$ & $105(49)$ \\
Exaggerated response to ibuprofen (\%) & $0(0)$ & $0(0)$ & $1 / 13(8)$ & $3 / 22(14)$ & $4 / 13(31)$ \\
\hline
\end{tabular}

*One relative and one child with Crohn's disease did not complete the ibuprofen challenge 


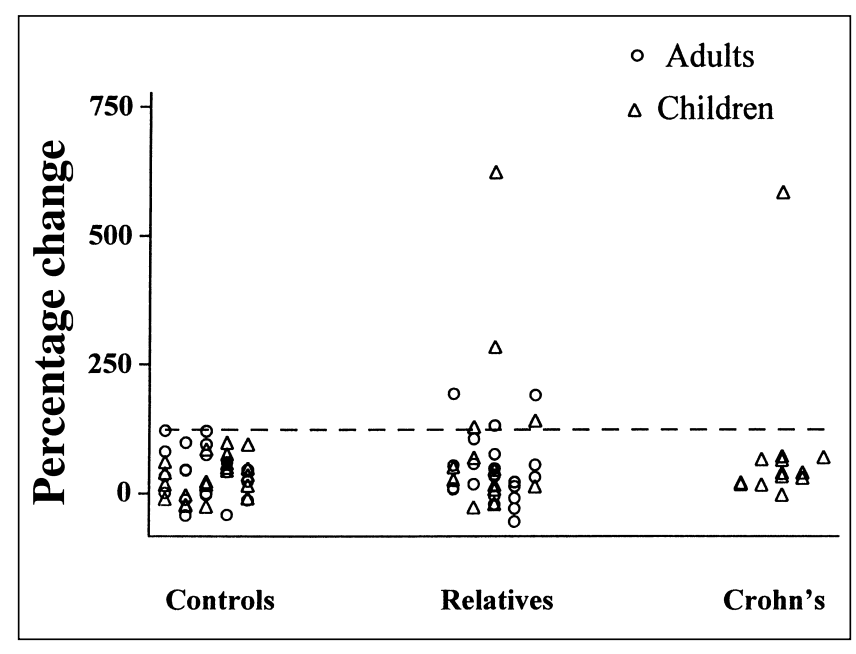

Figure 1) Change in lactulose-mannitol ratio postibuprofen. Seven subjects in the relatives group (20\%) and one child with Crohn's disease (8\%) had an increase above the upper limit of normal (dashed line is 123\%)

line LM ratios, a logarithm transformation was used to achieve normality, and the upper limit transformed back to the original data.

The upper reference limit for the percentage change in LM ratio was $123 \%$ above the baseline. The proportion of abnormal individuals was compared among groups by using the Fisher's exact test. Exploratory analyses were done to determine whether adults' intestinal permeability was different from that of children.

\section{RESULTS}

Permeability tests were well tolerated, and none of the children with Crohn's disease completing the ibuprofen challenge had a flare up of the disease attributable to the test. Demographic characteristics of study subjects are shown in Table 1. Relatives and controls were similar in terms of age and sex. The proportion of smokers was higher in adult controls than in adult relatives, but this difference was not statistically significant. The majority of children with Crohn's disease had small and large bowel involvement (10 of 14) and were receiving medical therapy (13 of 14). Baseline LM ratio and postibuprofen percentage change in LM ratio are presented in Table 2.

Children in both the control and relative groups appeared to have higher baseline LM ratios than adults; however, this difference did not reach statistical significance. If children and adults were considered together, the median baseline $\mathrm{LM}$ ratio in relatives $(0.0176)$ was similar to that in controls $(0.0165)$. The median baseline LM ratio in children with Crohn's disease $(0.0271)$ was significantly higher than in control children $(\mathrm{P}<0.001)$. One of 41 subjects in the control group (2\%) and two of 36 in the relatives group (6\%) had a baseline $\mathrm{LM}$ ratio above the upper reference limit. Baseline intestinal permeability was not significantly different between smokers and nonsmokers.

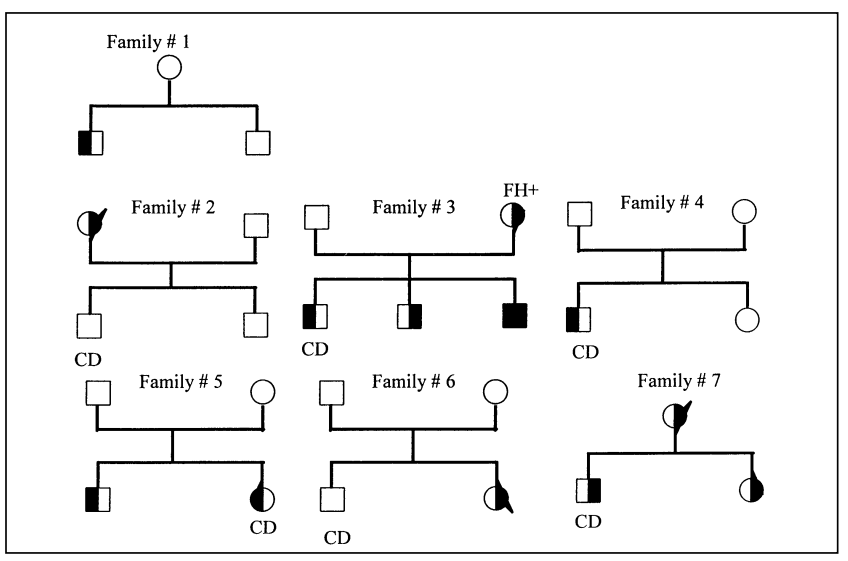

Figure 2) One control (Family 1) and six families of children with Crohn's disease (Families 2 to 7) had abnormalities of intestinal permeability. Open circles and squares indicate normal females and males, respectively; left shaded figures indicate abnormal baseline intestinal permeability; and right shaded figures indicate exaggerated response to ibuprofen. CD Crohn's disease; FH+ Positive family history for Crohn's disease

No subject in the control group and one of $13(8 \%)$ subjects in the group of children with Crohn's disease $(8 \%)$ had a response to ibuprofen above the upper reference limit. Seven relatives (three parents and four siblings) had a percentage increase in LM ratio postibuprofen above the upper reference limit. Thus, the proportion of relatives with an exaggerated response to ibuprofen (seven of 35 [20\%], 95\% CI 7\% to $33 \%$ ) was significantly higher than that in controls $(\mathrm{P}=0.003)$. When smokers (four adults and no children in the group of relatives were current smokers) were excluded from the analysis, the proportion of relatives with an exaggerated response to ibuprofen remained higher than that in controls $(16 \%$ versus $0 \%$, respectively; Fisher's exact test $\mathrm{P}=0.06$ ). In the group of relatives of children with Crohn's disease, the exaggerated response to ibuprofen was more frequent among siblings (four of 13 [31\%]) than among their parents (three of 22 [14\%]), and the children appeared to have a greater percentage change in LM ratio postibuprofen than adults ( $105 \%$ versus $44 \%$ respectively), but this difference did not reach statistical significance. The mean percentage change in LM ratio postibuprofen in relatives (mean 66\%, SE 20\%) and in children with Crohn's disease (mean $81 \%$, SE $43 \%$ ) was higher than in the control group (mean 35\%, SE 7\%); however, these differences did not reach statistical significance.

Figure 1 shows the response to ibuprofen challenge (expressed as the percentage change in the LM ratio between the baseline and the postibuprofen permeability studies) in the three study groups. Figure 2 shows the pedigrees of the families with abnormalities of intestinal permeability. When children with Crohn's disease (in whom abnormalities of intestinal permeability are expected) were excluded from the analysis, the proportion of families with abnormalities of intestinal permeability was higher in the Crohn's group (five of 14 [36\%]) than in the control 
group (one of 14 [7.1\%]), but this difference did not reach statistical significance (Fisher's exact test $\mathrm{P}=0.17$ ).

\section{DISCUSSION}

Hollander et al (7) were the first to suggest in 1986 that healthy, first-degree relatives of patients with Crohn's disease have increased intestinal permeability. This generated the hypothesis that abnormal intestinal permeability may be a primary defect in Crohn's disease families, leading to the exposure of the gastrointestinal immune system to an excessive antigen load, which initiates an intestinal inflammatory response in some family members that progresses to the development of inflammatory bowel disease.

The present study aimed to assess intestinal permeability in healthy, first-degree relatives (the parents and siblings) of a pediatric population of patients with Crohn's disease to determine whether these first-degree relatives had an exaggerated response to ibuprofen. By measuring intestinal permeability in the complete family (the parents and siblings) of children with known Crohn's disease, we also expected to obtain information regarding the consistency of abnormalities of intestinal permeability within families. Abnormalities in intestinal permeability in relatives of children with Crohn's disease were not apparent using the standard LM permeability test but were detected in response to the ibuprofen challenge. This is in agreement with previous studies $(17,18)$ and suggests that members of a subset of asymptomatic and apparently healthy members of families with Crohn's disease (20\%, $95 \%$ CI $7 \%$ to $33 \%$ ) demonstrate an exaggerated response to NSAIDs. The exaggerated response to ibuprofen was more frequent among siblings of children with Crohn's disease (four of 13 [31\%]) than among their parents (three of 22 [14\%]), but this difference was not significant. If the difference could be shown to be significant in a larger study group it would suggest that genetic predisposition (more closely shared by siblings) may be more important than environmental factors (shared by both parents and siblings) in the pathophysiology of increased intestinal permeability. Alternatively, it may be that age is an important factor in determining susceptability to environmental triggers (children may be more susceptible than adults). Evidence of a recessive model of transmission in Crohn's disease has been found by using segregation analysis $(26,27)$; therefore, our findings are compatible with a genetic link between abnormalities of intestinal permeability and Crohn's disease. The limited number of family pedigrees available suggests concordance in the type of permeability response in families where multiple individuals exhibit abnormal permeability tests. Whether abnormalities of intestinal permeability are a primary defect in families with Crohn's disease or merely secondary to inflammation remains an unresolved issue. The findings of the present study are important in either case because even if the abnormalities of intestinal permeability are secondary to inflammation, they may reflect subclinical disease in the subset of healthy, first-degree relatives of patients with Crohn's disease.

Our initial sample size estimation was based on data from Hilsden et al (18). If it is assumed that $20 \%$ of relatives and $1 \%$ of controls would have an abnormal response, approximately 50 subjects are required in each group to detect a difference between relatives and controls with a power of $80 \%$ and an alpha level of 0.05 . Recruitment of families of patients with Crohn's disease and control families fell short of the goal of 50 subjects/group (36 relatives and 41 controls, Table 1 ), which may explain why some of the apparent differences (eg, higher baseline LM ratios in children versus adults, a greater percentage change in LM ratio postibuprofen in children versus adults in the relatives group, and the mean percentage change in LM ratio postibuprofen in relatives and in children with Crohn's disease versus the control group) did not reach statistical significance.

Children with Crohn's disease demonstrated increased baseline intestinal permeability. This is in accordance with previous data in both adults $(28-30)$ and pediatric Crohn's disease patients $(31-33)$. In response to the ibuprofen challenge, children with Crohn's disease did not generally demonstrate an exaggerated response. This may be partially explained by the fact that almost half of these patients were considered steroid dependent and were being maintained in clinical remission on low dose daily steroid therapy, which may have blunted the response to the NSAID challenge.

There is some suggestion from this study that children have higher intestinal permeability than adults (Table 2), and the inclusion of children in our control group generated an upper reference limit for baseline LM ratios above those used in our previous studies on adults $(16,18)$. Data from a previous study using a slightly different protocol for the LM permeability test demonstrated a similar difference without reaching statistical significance (34).

It has been suggested that smoking can decrease intestinal permeability $(35,36)$, but this remains debated $(18,37,38)$. The proportion of adult smokers in the control group was higher than that in the relatives of Crohn's patients group. Although this difference was not statistically significant, if smoking effectively decreases intestinal permeability, results may still have been confounded if intestinal permeability was lowered in the control group more than in the relatives group. However, intestinal permeability did not appear to differ between smokers and nonsmokers. Furthermore, when smokers were excluded from the analysis, the proportion of individuals with an exaggerated response to ibuprofen remained higher in the relatives group than in the controls group.

\section{CONCLUSIONS}

Members of a subset of apparently healthy first-degree relatives of pediatric Crohn's disease patients demonstrate an exaggerated response to NSAID challenge. This abnormality is more common among siblings than parents and is 
compatible with there being a genetic link between abnormalities of intestinal permeability and Crohn's disease.

ACKNOWLEDGEMENTS: Dr Zamora was supported during his fellowship training in Pediatric Gastroenterology and Nutrition by the Swiss Foundation Eugenio Litta, the Swiss Society for Gastroenterology and Hepatology, and the Alberta Children's Hospital Research Foundation. Operating funds for this research protocol were obtained from a competitive award funded by the Children's Hospital Research Foundation. These data have been previously published in abstract form (39) and were presented in Washington, DC at the 1997 annual meeting of the American Association of Gastroenterology.

\section{REFERENCES}

1. Orholm M, Munkholm P, Langholz E, Nielsen OH, Sorensen IA, Binder V. Familial occurrence of inflammatory bowel disease. $\mathrm{N}$ Engl J Med 1991;324:84-8.

2. Fielding JF. The relative risk of inflammatory bowel disease among parents and siblings of Crohn's disease patients. J Clin Gastroenterol 1986;8:655-7.

3. Lashner BA, Evans AA, Kirsner JB, Hanauer SB. Prevalence and incidence of inflammatory bowel disease in family members. Gastroenterology 1986;91:1396-400.

4. Mayberry JF, Rhodes J, Newcombe RG. Familial prevalence of inflammatory bowel disease in relatives of patients with Crohn's disease. Br Med J 1980;280:84.

5. Weterman IT, Pena AS. Familial incidence of Crohn's disease in The Netherlands and a review of the literature. Gastroenterology 1984;86:449-52.

6. Yang H, McElree C, Roth M-P, Shanahan F, Targan SR, Rotter JI. Familial empirical risks for inflammatory bowel disease: Differences between Jews and non-Jews. Gut 1993;34:517-24.

7. Hollander D, Vadheim CM, Brettholz E, Petersen GM, Delahunty $\mathrm{T}$, Rotter JI. Increased intestinal permeability in patients with Crohn's disease and their relatives. Ann Intern Med 1986;105:883-5.

8. Ainsworth M, Erikson J, Rasmussen JW, Schaffalitzky de Muckadell OB. ${ }^{51} \mathrm{Cr}$-labelled ethylenediaminetetraacetic acid in patients with Crohn's disease and their healthy relatives. Scand J Gastroenterol 1989;24:993-8.

9. Howden CW, Gillanders I, Morris AJ, Duncan A, Daneh B, Russell RI. Intestinal permeability in patients with Crohn's disease and their first-degree relatives. Am J Gastroenterol 1994;89:1175-6.

10. Katz KD, Hollander D, Vadheim CM, et al. Intestinal permeability in patients with Crohn's disease and their healthy relatives. Gastroenterology 1989;97:927-31.

11. Munkholm P, Langholz E, Hollander D, et al. Intestinal permeability in patients with Crohn's disease and ulcerative colitis and their first degree relatives. Gut 1994;35:68-72.

12. Ruttenberg D, Young GO, Wright JP, Isaacs S. Peg-400 excretion in patients with Crohn's disease, their first-degree relatives, and healthy volunteers. Dig Dis Sci 1992;37:705-8.

13. Teahon K, Smethurst P, Levi AJ, Menzies IS, Bjarnason I.
Intestinal permeability in patients with Crohn's disease and their first degree relatives. Gut 1992;33:320-3.

14. Valpiani D, Ornigotti L, Rossellini SR. Intestinal permeability in patients with Crohn's disease and first grade relatives. Gastroenterology 1992;102:A708. (Abst)

15. Lindberg E, Soderholm JD, Olaison G, Jarnerot G. Intestinal permeability to polyethylene glycols in monozygotic twins with Crohn's disease. Scand J Gastroenterol 1995;30:780-3.

16. May GR, Sutherland LR, Meddings JB. Is small intestinal permeability really increased in relatives of patients with Crohn's disease? Gastroenterology 1993;104:1627-32.

17. Pironi L, Miglioli M, Ruggeri E, et al Effect of non-steroidal anti-inflammatory drugs (NSAID) on intestinal permeability of first degree relatives of patients with Crohn's disease. Gastroenterology 1992;102:A679. (Abst)

18. Hilsden RJ, Meddings JB, Sutherland LR. Intestinal permeability changes in response to acetylsalicylic acid in relatives of patients with Crohn's disease. Gastroenterology 1996;110:1395-403.

19. Singer HC, Anderson JG, Frischer H, Kirsner JB. Familial aspects of inflammatory bowel disease. Gastroenterology 1971;61:423-30.

20. Polito JM, Rees RC, Childs B, Mendeloff AI, Harris ML, Bayless TM. Preliminary evidence for genetic anticipation in Crohn's disease. Lancet 1996;347:798-800.

21. Colombel JF, Grandbastien B, Gower-rousseau C, et al. Clinical characteristics of Crohn's disease in 72 families. Gastroenterology 1996;111:604-7.

22. Polito JM II, Childs B, Mellits ED, Tokayer AZ, Harris ML, Bayless TM. Crohn's disease: Influence of age at diagnosis on site and clinical type of disease. Gastroenterology 1996;111:580-6.

23. Satsangi J, Grootscholten C, Holt H, Jewell DP. Clinical patterns of familial inflammatory bowel disease. Gut 1996;38:738-41.

24. Griffiths A, Harris K, Smith C, et al. Is there "anticipation" in familial Crohn's disease? Gastroenterology 1997;112:A985. (Abst)

25. Hyams JS, Ferry GD, Mandel FS, et al. Development and validation of a pediatric Crohn's disease activity index. J Pediatr Gastroenterol Nutr 1991;12:439-47.

26. Kuster W, Pascoe L, Purrmann J, Funk S, Majewski F. The genetics of Crohn disease: complex segregation analysis of a family study with 265 patients with Crohn disease and 5,387 relatives. Am J Med Genet 1989;32:105-8.

27. Orholm M, Iselius L, Sorensen TI, Munkholm P, Langholz E, Binder V. Investigation of inheritance of chronic inflammatory bowel diseases by complex segregation analysis. Br Med J 1993;306:20-4.

28. Bjarnason I, O'Morain C, Levi AJ, Peters TJ. Absorption of 51-Chromium-labeled ethylendiaminetetraacetate in inflammatory bowel disease. Gastroenterology 1983;85:18-22.

29. Ukabam SO, Clamp JR, Cooper BT. Abnormal small intestinal permeability to sugars in patients with Crohn's disease of the terminal ileum and colon. Digestion 1983;27:70-4.

30. Olaison G, Leandersson P, Sjodahl R, Tagesson C. Intestinal permeability to polyethylene glycol 600 in Crohn's disease. Preoperative determination in a defined segment of small intestine. Gut 1988;29:196-9.

31. Issenman RM, Jenkins RT, Radoja C. Intestinal permeability compared in pediatric patients and adults patients with inflammatory bowel disease. Clin Invest Med 1993;16:187-96.

32. Murphy MS, Eastham EJ, Nelson R, Pearson AD, Laker MF. Intestinal permeability in Crohn's disease. Arch Dis Child 1989;64:321-5. 
33. Turck $\mathrm{D}$, Ythier $\mathrm{H}$, Maquet $\mathrm{E}$, et al. Intestinal permeability to [51Cr]EDTA in children with Crohn's disease and celiac disease. J Pediatr Gastroenterol Nutr 1987;6:535-7.

34. Van Elburg RM, Uil JJ, Kokke FTM, et al. Repeatability of the sugar-absorption test, using lactulose and mannitol, for measuring intestinal permeability for sugars. J Pediatr Gastroenterol Nutr 1995;20:184-8.

35. Prytz H, Benoni C, Tagesson C. Does smoking tighten the gut? Scand J Gastroenterol 1989;24:1084-8.

36. Den Hond E, Peeters M, Ghoos Y, et al. The increase of intestinal permeability caused by oral indomethacin is reduced by smoking. Gastroenterology 1997;112:A957. (Abst)

37. Soderholm J, Olaison G, Sjodahl R, Tagesson C. Smoking and intestinal absorption of oral polyethylene glycols in Crohn's disease. Scand J Gastroenterol 1993;28:163-7.

38. Cope GF, Goode HF, Heatley RV, Kelleher J. Measurement of intestinal permeability by high pressure chromatography, the effect of cigarette smoking. Clin Sci 1988;75(Suppl 19):8. (Abst)

39. Zamora SA, Scott RB, Butzner DJ, Hilsden RJ, Meddings J, Sutherland LR. Intestinal permeability before and after ibuprofen in families of children with Crohn's disease. Gastroenterology 1997;112:A1127. (Abst) 


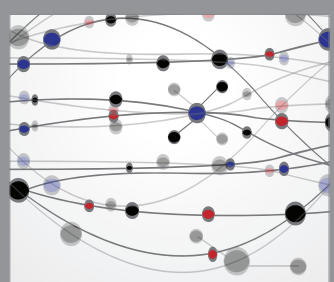

The Scientific World Journal
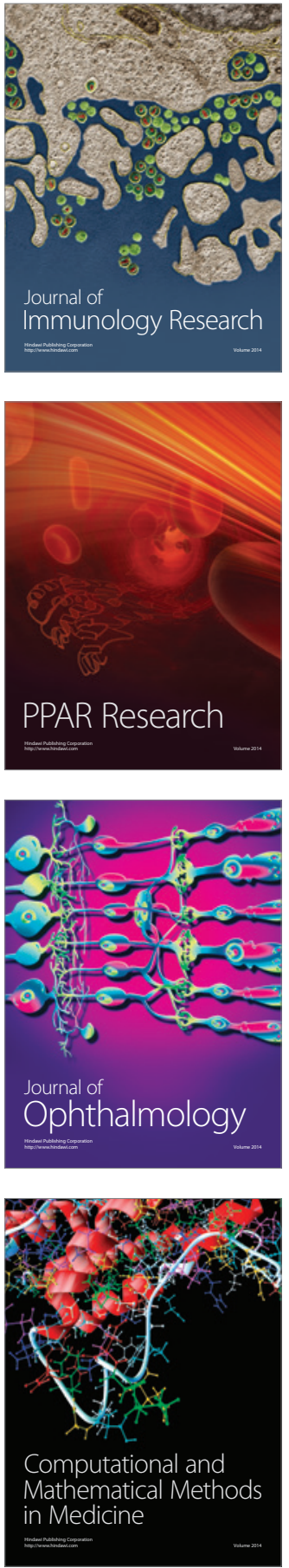

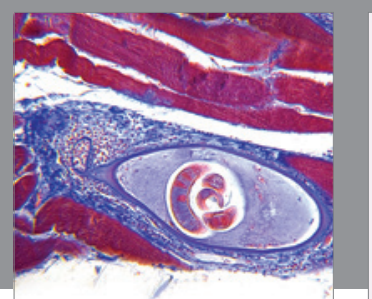

Gastroenterology Research and Practice

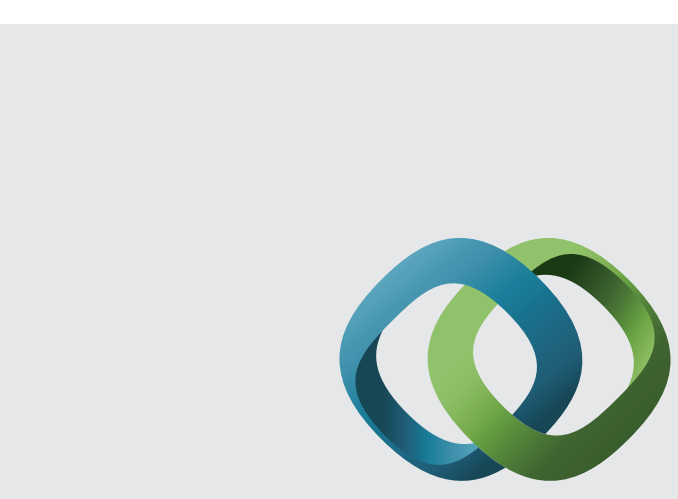

\section{Hindawi}

Submit your manuscripts at

http://www.hindawi.com
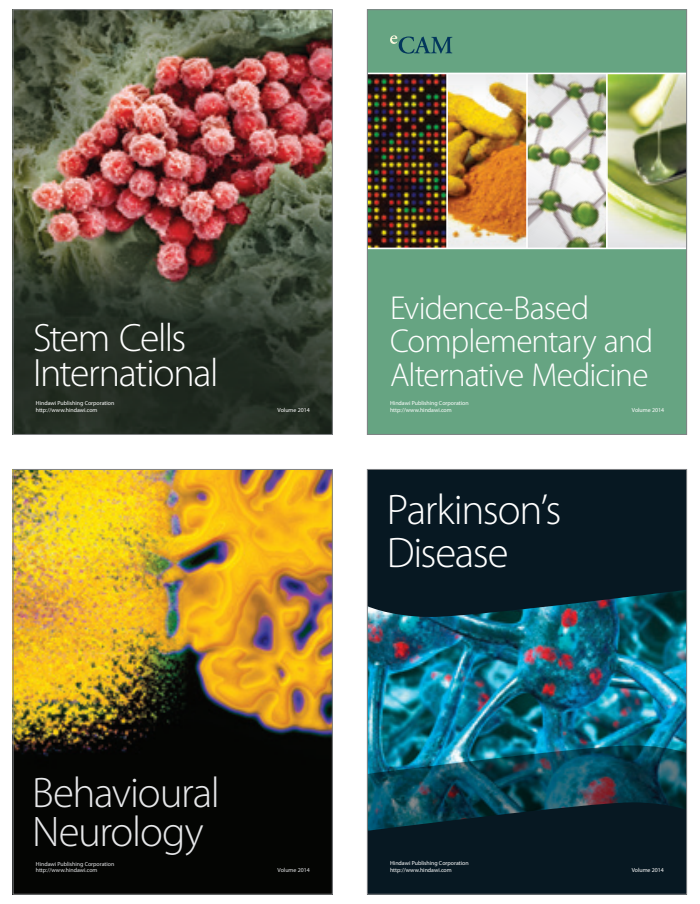
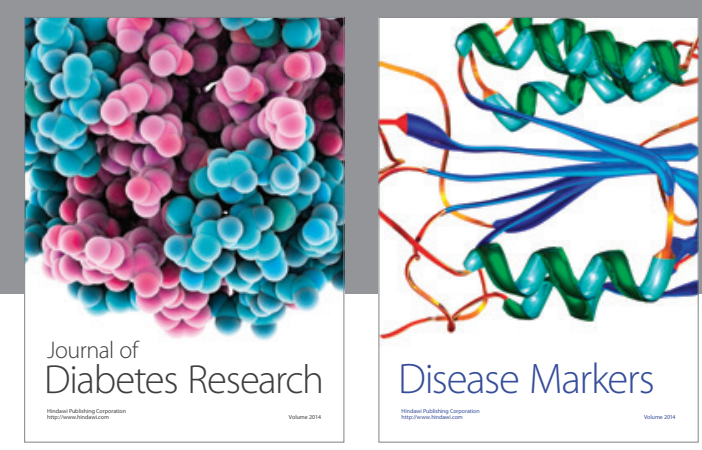

Disease Markers
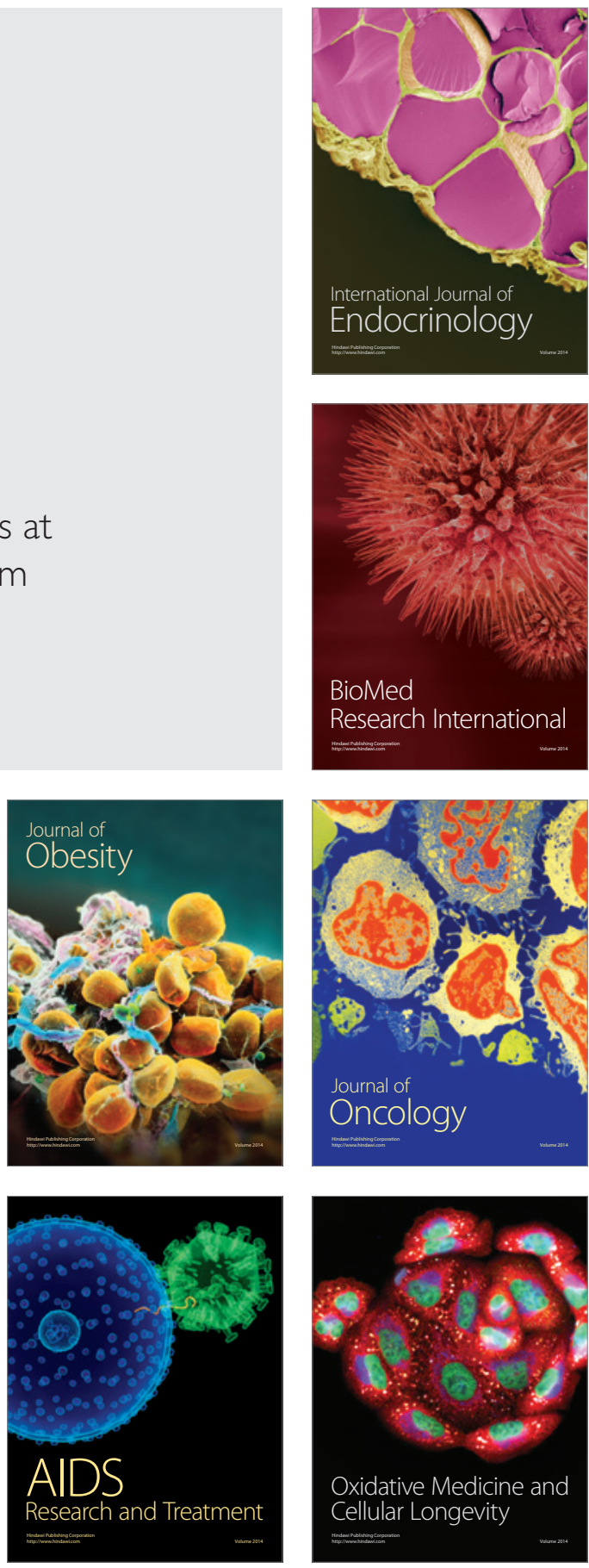